\title{
The MAGE protein family and cancer
}

\author{
Jenny L. Weon and Patrick Ryan Potts* \\ Departments of Physiology, Pharmacology, and Biochemistry \\ UT Southwestern Medical Center, Dallas, TX 75390
}

*Correspondence: Patrick Ryan Potts, 5323 Harry Hines Blvd, Dallas, TX 75390-9040

Ryan.Potts@UTSouthwestern.edu (214) 648-1493 


\begin{abstract}
The Melanoma Antigen Gene (MAGE) protein family is a large, highly conserved group of proteins that share a common MAGE homology domain. Intriguingly, many MAGE proteins are restricted in expression to reproductive tissues, but are aberrantly expressed in a wide-variety of cancer types. Originally discovered as antigens on tumor cells and developed as cancer immunotherapy targets, recent literature suggests a more prominent role for MAGEs in driving tumorigenesis. This review will highlight recent developments into the function of MAGEs as oncogenes, their mechanisms of action in regulation of ubiquitin ligases, and outstanding questions in the field.
\end{abstract}

\title{
Introduction
}

The Melanoma Antigen Gene (MAGE) family has garnered growing interest as biomarkers in cancer and targets of immunotherapies because a subset of these $>40$ human proteins are classified as cancer-testis antigens (CTAs), which have restricted expression to the testis (and occasionally ovary and placenta) and are aberrantly re-expressed in cancer where they can be immunogenic (reviewed in [1]). Collectively, MAGEs have been found to be broadly expressed in many tumor types, including colon [2], melanoma [3,4], brain [5], lung [6-8], prostate [9], and breast $[10,11]$, among others. For many years, the focus on MAGE CTAs was centered on their 
potential for cancer immunotherapy. However, this approach has had little success and met recent challenges. Detailed functional studies of these proteins have started to emerge and suggest that their expression in cancer is not simply due to non-specific, progressive promoter demethylation due to global genomic instability in cancer. MAGE genes are associated with hallmarks of aggressive cancers, including worse clinical prognosis, increased tumor growth, metastases, and enrichment in stem cell-like populations. Importantly, functional studies have shown that some MAGE CTAs can have non-overlapping oncogenic driver activity. Thus,

MAGE CTAs may provide a novel means to develop cancer-specific therapeutics to treat a broad range of cancers.

\section{MAGE Family of Proteins}

MAGE genes are conserved in all eukaryotes and have rapidly expanded in gene number in mammals (Figure 1). Members of the human MAGE family can be divided into two categories based on tissue expression pattern: Type I MAGEs are considered CTAs and in humans include the MAGE-A, -B, and -C subfamily members which are clustered on the X-chromosome (reviewed in [1,12]). Type II MAGEs (MAGE-D, -E, -F, -G, -H, -L subfamilies and Necdin) are expressed throughout many tissues in the body and are not restricted to the $\mathrm{X}$ chromosome (reviewed in [12]). Both type I and type II MAGEs contain a MAGE homology domain (MHD) 
that is approximately 170 amino acids (Figure 2A), which on average is $46 \%$ conserved amongst all human MAGEs [13]. Structural studies have revealed that the MHD consists of tandem winged helix motifs (Figure 2B-D) [13]. Our lab has shown that a defining biochemical function of MAGEs is their ability to bind to specific E3 RING ubiquitin ligases through their MHDs (Table 1), which may alter the relative orientation of the two winged helix motifs (compare Figure 2B-C with 2D) [13]. Importantly, we and others have determined that MAGEs can regulate the ubiquitination of proteins through modulating the activity of their cognate E3 ligase. This includes, enhancing general ligase activity, binding to and specifying novel substrates for ubiquitination by the E3 ligase complex, and altering the subcellular localization of E3 ligases to dictate substrates (Figure 2E) [13-15]. Thus, aberrant expression of MAGEs in tumor cells can lead to alterations in cellular processes and signaling pathways through ubiquitination and potentially other activities to contribute to tumorigenesis.

\section{MAGEs are associated with poor clinical prognosis}

Extensive studies of MAGE expression in various cancers (Table 2) have shown their predictive association with poor clinical outcomes. For example, MAGE-A3 and -A9 expression is significantly correlated with decreased survival in non-small cell lung cancers $[7,16]$ and MAGE-A3, -A6, and -C2 expression in breast cancers is significantly associated with estrogen 
receptor-negative or progesterone receptor-negative status, higher grade tumors, and correlated with worse outcome $[11,17]$. In ovarian cancers, MAGE-A1, -A9, and -A10 expression are associated with worse prognosis $[18,19]$. MAGEs are also associated with increased rates of recurrence after therapy. In gastric carcinoma, MAGE-A1-6 expression in peritoneal washes after cancer resection correlated with a significant decreased disease-free survival rate [20], and in hepatocellular carcinoma MAGE-A9 expression was significantly correlated with decreased disease-free survival, advanced tumor grade, metastasis, portal vein invasion, and overall survival [21].

\section{MAGE CTAs have oncogenic activity}

MAGEs are not only associated with poor clinical prognosis, but recent reports suggest they

function as drivers of tumorigenesis. Upon expression, multiple cancer types become addicted to MAGEs for viability, such as MAGE-As or MAGE-Cs in breast [15], lung [15], colon [15], mast cells [22], multiple myeloma [23], and melanoma [24]. MAGE-A3 and -C2 expression in cancer lines has been shown to increase invasive potential in vitro [17,25]. Furthermore, MAGE-A3 and -A6 promote the transformation of fibroblasts and increased soft agar growth of cancer cells [15].

More impressively, MAGE-A6 promotes anchorage-independent growth of normal diploid colonic epithelial cells [15]. In addition, MAGEs enhance tumor formation in vivo. Orthotopic 
xenografts of MAGE-A3 overexpressing human thyroid carcinoma cells exhibited increased tumor growth and metastases to the lung [25], and MAGE-C knockdown delayed tumor formation of metastatic melanoma in vivo [26]. Furthermore, MAGE-B knockdown suppressed the growth of melanoma cells in a syngeneic mouse tumor model [24]. These studies suggest that MAGE CTAs may have oncogenic activity and additional rigorous studies in genetically engineered models of cancer in mice are warranted. Additionally, the contribution and activities of specific MAGEs (including many MAGE-B genes) needs further investigation.

\section{Mechanism in cancer development and progression}

Although mechanistic studies of MAGEs are limited, there is a growing body of evidence for their interactions with other proteins, especially E3 ubiquitin ligases. The MHDs of MAGE-A2, $\mathrm{A} 3$, -A6, and -C2 can bind to the coiled-coil domain of the TRIM28/KAP1 ubiquitin ligase [13,24]. MAGE-C2 increases phosphorylation of TRIM28/KAP1 and improves DNA repair after double-stranded breaks, possibly by enhancing complex formation between TRIM28/KAP1 and ATM [26]. Our lab and others have shown that MAGE binding can enhance TRIM28/KAP1's ubiquitin ligase activity against $\mathrm{p53}$, resulting in its degradation in a proteasome-dependent manner $[13,27]$. In the presence of wild-type p53, knockdown of MAGE-A genes appears to increase p53 recruitment to target promoters [28] and increase mRNA levels of p53 
transcriptional targets [27,28]. Others have also suggested that MAGE-A binds to p53 DNAbinding domain directly which may prevent its transcriptional activity [28,29]. Additionally, MAGE-As and -C2 may downregulate p53 activity through preventing its acetylation [24] at promyelocytic leukemia (PML) nuclear bodies by recruiting HDAC3 [29] and blocking p300mediated PML acetylation [30].

However, the relevance of MAGE-As in cancer is not limited in scope to modulating p53 function. Expression of MAGE-A3 or -A6 does not correlate with p53 mutation status in multiple tumor types [15]. Most recently, our lab has determined the MAGE-A3-TRIM28 and MAGE-A6-TRIM28 ligase complexes can ubiquitinate the alpha catalytic subunit (PRKAA1) of the tumor suppressor AMPK that functions as the master cellular energy sensor and regulator $[15,31,32]$. This event leads to AMPK degradation and reduction of overall AMPK protein levels in tumors [15]. Furthermore, downregulation of AMPK by MAGE-A3 and -A6 led to significantly decreased autophagy levels and upregulation of mTOR signaling [15], which may provide the optimal environment for early tumor formation and growth [33-35]. Importantly, use of AMPK agonists significantly decreased MAGE-A6-mediated anchorage-independent growth in vitro [15]. Because AMPK agonists (e.g. metformin) and mTOR inhibitors (e.g. everolimus) are already in use in the clinic [36,37], an immediate applicable point of these results may be to utilize MAGE-A3 and -A6 as a biomarkers for effective use of these drugs [15]. 
MAGE-A11 is unique among the type I MAGEs in that it is known to be involved in the regulation of hormonal signals in prostate cancer $[9,38]$. Binding of MAGE-A11 to the Nterminal FXXLF motif of the androgen receptor (AR) facilitates SRC/p160 co-activator binding [38]. Transcriptional activity of AR was also enhanced by epidermal growth factor (EGF)mediated phosphorylation and ubiquitination of MAGE-A11 [39]. In addition to modulating hormone signaling, MAGE-A11 may play a role in mediating survival of tumors in stressful conditions (such as when tumors outgrow their blood supply) by stabilizing HIF-1alpha levels, possibly by binding to and inhibiting PHD2, a prolyl 4-hydroxylase which modulates HIF-1alpha stability [40].

\section{MAGEs and cancer stem cells}

In addition to their ability to function as oncogenes, MAGEs are enriched in the stem cell population of certain cancers. MAGE-A3 has much higher expression in a cancer stem cell-like side population in bladder cancer, which compared to the main population, exhibited more robust tumor growth in vivo [41]. Additionally, MAGE-A2, -A3, -A4, -A6, -A12, and -B2 are highly enriched in the stem cell-like side population of multiple cancer cell lines [42]. Furthermore, analysis across the maturation stages of B-cells demonstrated that MAGE-C1 is expressed with high frequency in CD34+ stem cells and early to immature B-cells (CD10+ or CD19+) [43], 
suggesting that MAGE-C1 may be intimately related to the initiating cell population in this

disease. Consistently, MAGE-C1 correlates with decreased time to relapse after allogeneic stem cell transplant [44] and decreased overall survival [44,45]. Whether MAGEs contribute to maintenance of cancer stem cells within tumors will need to be examined.

\section{Transcriptional regulation of MAGEs in cancer}

Determining the regulatory processes controlling the aberrant re-expression of MAGEs in cancer may provide insight into potential drug targets for MAGE-expressing tumors. The use of demethylating agents such as 5-aza-2-deoxycytidine (5DC) can induce expression of MAGE-A1 in cell lines derived from malignant tumors [46,47], and this effect can be augmented through the use of trichostatin A, an HDAC inhibitor $[48,49]$. This suggests that type I MAGEs are not normally expressed in somatic cells due to methylation of $\mathrm{CpG}$ islands in their promoter regions. Mechanisms proposed for the demethylation of type I MAGE promoters include the deregulation of KIT tyrosine kinase activity [50] and the FGFR2-IIIb that was found to be a putative upstream regulator of MAGE-A3/6 expression [51]. Fibronectin knockdown also led to increased MAGEA3 expression [25]. Fibronectin signaling through integrin receptors, FGFR2 signaling, and the c-KIT pathway all involve the PI3K/Akt [52-54] and Ras pathways [54-56], suggesting that these pathways may be the key to understanding how type I MAGEs are turned on in cancer cells. 
In addition to $\mathrm{CpG}$ promoter demethylation, several studies have implicated additional transcriptional regulation of MAGEs in cancer. In one study, 5DC was not able to induce MAGE-A1 in several normal diploid cell lines [46], indicating that there may be more involved in the regulation of these CTAs than simply $\mathrm{CpG}$ demethylation. However, 5DC was able to induce MAGE-A1, -A2, -B1, and -B4 expression in normal XY karyotype human dermal fibroblasts [57]. Brother of the Regulator of Imprinted Sites (BORIS) is a CTA and transcription factor that was found to induce the expression of MAGE CTAs in normal human dermal fibroblasts and cancer lines [48,57]. In addition, the Ets-1 and Sp1 transcription factors may potentially play a role in promoting expression of MAGE CTAs, but MAGE promoter demethylation is a prerequisite [58,59]. The relevance of these factors in the regulation of MAGE expression is intriguing and should be further defined in the context of cancer progression.

\section{MAGE-based therapy: from immunotherapies to direct targeting}

The relatively restricted expression of MAGEs and their antigenicity has spurred research into utilizing them as targets for immunotherapies. In the largest therapeutic trial in lung cancer, MAGRIT (MAGE-A3 as Adjuvant Non-Small Cell Lung Cancer Immunotherapy), recombinant MAGE-A3 protein was injected in approximately 2,700 patients after lung cancer tumor 
resection [60]. Although the MAGE-A3 vaccine was well-tolerated by patients, the phase III

clinical trial failed to demonstrate an increase in disease-free survival versus placebo [61].

Additionally, there have been unexpected deaths in anti-MAGE T-cell-based therapies due to cross-reactivity to unrelated proteins and to certain MAGEs found at low levels in normal brain $[62,63]$. These examples demonstrate the critical need to further pursue rigorous, detailed studies of MAGE expression across normal tissues and suggest that mechanistic studies of the MAGE proteins may offer valuable, alternative approaches to targeting a wide spectrum of cancers. For example, targeting MAGE-E3 ligase interactions, inhibiting MAGE-A11 binding to the androgen receptor in prostate cancers, and disrupting MAGE-A3/6 interaction with AMPK $\alpha 1$ or using AMPK agonists or mTOR inhibitors in MAGE-A positive cancers are all potential new routes to target the activity of MAGEs.

\section{Conclusions}

MAGEs are expressed in a wide-variety of cancers, but the transcriptional programs controlling their aberrant expression are unclear. MAGEs can drive tumor progression through various mechanisms, which ultimately result in more aggressive, metastatic tumors that have greater chance of recurrence. They are attractive targets of cancer therapy and more mechanistic studies of MAGE function in cancer will facilitate the development of targeted therapy across multiple 
types of cancers. Further study of MAGEs may facilitate determining their physiological

function in the testis and may elucidate the role of a conserved gametogenic program in the context of cancer. 
Table 1.

Summary of high confidence interactions between MAGEs and E3 ubiquitin ligases.

\begin{tabular}{|c|c|c|}
\hline MAGE & $\begin{array}{l}\text { E3 Ubiquitin } \\
\text { Ligase } \\
\end{array}$ & Target \\
\hline MAGE-A1 & TRIM31 [64] & Unknown \\
\hline MAGE-A2 & MDM2 [65] & $\begin{array}{l}\text { Inhibit MDM2-mediated ubiquitination of MDM4 } \\
\text { [65] }\end{array}$ \\
\hline $\begin{array}{l}\text { MAGE-A2, } \\
-\mathrm{A} 3,-\mathrm{A} 6,-\mathrm{C} 2\end{array}$ & $\begin{array}{c}\text { TRIM28/KAP1 } \\
{[13,24]}\end{array}$ & Ubiquitination and degradation of p53 [13] \\
\hline MAGE-A3 & $\begin{array}{l}\text { TRIM28/KAP1 } \\
{[13,24]}\end{array}$ & $\begin{array}{l}\text { Ubiquitination and degradation of KZNFs } \\
\text { containing } A+B \text { box KRAB domains [66] }\end{array}$ \\
\hline MAGE-A3, -A6 & $\begin{array}{c}\text { TRIM28/KAP1 } \\
{[13,24]}\end{array}$ & $\begin{array}{l}\text { Recruit AMPK alpha subunit for ubiquitination and } \\
\text { degradation [15] }\end{array}$ \\
\hline MAGE-A4 & TRIM69 [67] & Unknown \\
\hline MAGE-B18 & LNX1 [13] & Unknown \\
\hline MAGE-D1 & Praja1 [68] & $\begin{array}{l}\text { MAGE-D1 is ubiquitinated }[68,69] \text { and modulates } \\
\text { Dlx } 5 \text { transcription factor activity [68] }\end{array}$ \\
\hline MAGE-D1 & Unknown & $\begin{array}{l}\text { Ubiquitination of the serotonin transporter SERT } \\
\text { [72] }\end{array}$ \\
\hline MAGE-D1 & XIAP $[70,71]$ & Unknown \\
\hline MAGE-G1 & NSE1 $[13,73]$ & Unknown \\
\hline MAGE-L2 & TRIM27 [14] & $\begin{array}{l}\text { K63-ubiquitination of WASH for proper actin } \\
\text { assembly and endosomal protein recycling [14] }\end{array}$ \\
\hline Necdin & Unknown & Ubiquitination and degradation of PIAS1 [74] \\
\hline
\end{tabular}


Table 2.

Summary of select cancer subtypes with percent MAGE-positive patient tumors.

\begin{tabular}{|c|c|c|c|}
\hline Cancer Type & MAGE Gene & Percent & References \\
\hline $\begin{array}{l}\text { Lung, non- } \\
\text { small cell }\end{array}$ & $\begin{array}{c}\text { MAGE-A1 } \\
\text { MAGE-A3 } \\
\text { MAGE-A4 } \\
\text { MAGE-A6 } \\
\text { MAGE-A10 } \\
\text { MAGE-C1 }\end{array}$ & $\begin{array}{c}27-46 \% \\
38-55 \% \\
19-35 \% \\
26 \% \\
14-27 \% \\
19 \%-27 \%\end{array}$ & $\begin{array}{c}{[6-8]} \\
{[6-8]} \\
{[6-8]} \\
{[6]} \\
{[6-8]} \\
{[7,75]}\end{array}$ \\
\hline Melanoma & $\begin{array}{l}\text { MAGE-A1, primary tumor } \\
\text { MAGE-A1, metastases } \\
\text { MAGE-C1, primary tumor } \\
\text { MAGE-C1, metastases } \\
\text { MAGE-C2, primary tumor } \\
\text { MAGE-C2, metastases }\end{array}$ & $\begin{array}{c}16-20 \% \\
48-51 \% \\
24 \% \\
40 \% \\
33 \% \\
40 \%\end{array}$ & $\begin{array}{l}{[3,4]} \\
{[3,4]} \\
{[76]} \\
{[76]} \\
{[76]} \\
{[76]}\end{array}$ \\
\hline Breast & $\begin{array}{c}\text { MAGE-A1 } \\
\text { MAGE-A2 } \\
\text { MAGE-A3/6 } \\
\text { MAGE-A4 } \\
\text { MAGE-A9 } \\
\text { MAGE-A11 } \\
\text { MAGE-A12 } \\
\text { MAGE-C1 } \\
\text { MAGE-C2 }\end{array}$ & $\begin{array}{c}6 \% \\
19 \% \\
10-15 \% \\
13 \% \\
45 \% \\
67 \% \\
9 \% \\
14 \% \\
8 \%\end{array}$ & $\begin{array}{c}{[10]} \\
{[10]} \\
{[10,11]} \\
{[10]} \\
{[77]} \\
{[77]} \\
{[10]} \\
{[78]} \\
{[78]}\end{array}$ \\
\hline Ovarian & $\begin{array}{l}\text { MAGE-A1 } \\
\text { MAGE-A3 } \\
\text { MAGE-A4 } \\
\text { MAGE-A9 } \\
\text { MAGE-A10 } \\
\text { MAGE-C1 }\end{array}$ & $\begin{array}{c}15 \%-53 \% \\
36 \%-37 \% \\
47 \% \\
52 \% \\
37 \% \\
16 \%\end{array}$ & $\begin{array}{c}{[18,79]} \\
{[18,79]} \\
{[18]} \\
{[18]} \\
{[19]} \\
{[18]}\end{array}$ \\
\hline Colon & $\begin{array}{l}\text { MAGE-A1 } \\
\text { MAGE-A2 } \\
\text { MAGE-A3 } \\
\text { MAGE-A4 }\end{array}$ & $\begin{array}{c}12 \%-30 \% \\
28 \% \\
20-27 \% \\
22 \%\end{array}$ & $\begin{array}{c}{[2,80]} \\
{[2]} \\
{[2,80]} \\
{[80]}\end{array}$ \\
\hline $\begin{array}{l}\text { Multiple } \\
\text { myeloma }\end{array}$ & $\begin{array}{c}\text { MAGE-A1 } \\
\text { MAGE-A2 } \\
\text { MAGE-A3/6 } \\
\text { MAGE-A3/6, after relapse } \\
\text { MAGE-A12 } \\
\text { MAGE-C1 } \\
\text { MAGE-C2 }\end{array}$ & $\begin{array}{c}<10-26 \% \\
36 \% \\
37-41 \% \\
77 \% \\
20 \% \\
77 \% \\
50-59 \%\end{array}$ & $\begin{array}{c}{[27,45]} \\
{[45]} \\
{[27,45]} \\
{[27]} \\
{[45]} \\
{[27,45]} \\
{[27]}\end{array}$ \\
\hline
\end{tabular}




\section{Acknowledgements}

We apologize for the many publications we were unable to discuss and cite due to space

limitations. We thank members of the Potts lab for helpful discussions and critical reading of the manuscript. This work was supported by Michael L. Rosenberg Scholar in Medical Research fund (PRP), CPRIT R1117 (PRP), DOD Discovery Award W81XWH-12-1-0446 (PRP),

WELCH Foundation I-1821 (PRP), ACS IRG 02-196 (PRP), and NIH R01GM111332 (PRP),

\section{References and recommended reading}

Papers of particular interest, published within the period of review, have been highlighted as:

- of special interest

•• of outstanding interest

1. Simpson AJ, Caballero OL, Jungbluth A, Chen YT, Old LJ: Cancer/testis antigens, gametogenesis and cancer. Nat Rev Cancer 2005, 5:615-625.

2. Mori M, Inoue H, Mimori K, Shibuta K, Baba K, Nakashima H, Haraguchi M, Tsuji K, Ueo H, Barnard GF, et al.: Expression of MAGE genes in human colorectal carcinoma. Ann Surg 1996, 224:183-188.

3. Brasseur F, Rimoldi D, Lienard D, Lethe B, Carrel S, Arienti F, Suter L, Vanwijck R, Bourlond A, Humblet Y, et al.: Expression of MAGE genes in primary and metastatic cutaneous melanoma. Int J Cancer 1995, 63:375-380.

4. Barrow C, Browning J, MacGregor D, Davis ID, Sturrock S, Jungbluth AA, Cebon J: Tumor antigen expression in melanoma varies according to antigen and stage. Clin Cancer Res 2006, 12:764-771. 
5. Scarcella DL, Chow CW, Gonzales MF, Economou C, Brasseur F, Ashley DM: Expression of MAGE and GAGE in high-grade brain tumors: a potential target for specific immunotherapy and diagnostic markers. Clin Cancer Res 1999, 5:335-341.

6. Tajima K, Obata Y, Tamaki H, Yoshida M, Chen YT, Scanlan MJ, Old LJ, Kuwano H, Takahashi T, Takahashi T, et al.: Expression of cancer/testis (CT) antigens in lung cancer. Lung Cancer 2003, 42:23-33.

7. Gure AO, Chua R, Williamson B, Gonen M, Ferrera CA, Gnjatic S, Ritter G, Simpson AJ, Chen YT, Old LJ, et al.: Cancer-testis genes are coordinately expressed and are markers of poor outcome in non-small cell lung cancer. Clin Cancer Res 2005, 11:8055-8062.

8. Kim YD, Park HR, Song MH, Shin DH, Lee CH, Lee MK, Lee SY: Pattern of cancer/testis antigen expression in lung cancer patients. Int J Mol Med 2012, 29:656-662.

9. Karpf AR, Bai S, James SR, Mohler JL, Wilson EM: Increased expression of androgen receptor coregulator MAGE-11 in prostate cancer by DNA hypomethylation and cyclic AMP. Mol Cancer Res 2009, 7:523-535.

10. Otte M, Zafrakas M, Riethdorf L, Pichlmeier U, Loning T, Janicke F, Pantel K: MAGE-A gene expression pattern in primary breast cancer. Cancer Res 2001, 61:6682-6687.

11. Ayyoub M, Scarlata CM, Hamai A, Pignon P, Valmori D: Expression of MAGE-A3/6 in primary breast cancer is associated with hormone receptor negative status, high histologic grade, and poor survival. J Immunother 2014, 37:73-76.

12. Barker PA, Salehi A: The MAGE proteins: emerging roles in cell cycle progression, apoptosis, and neurogenetic disease. J Neurosci Res 2002, 67:705-712.

13. Doyle JM, Gao J, Wang J, Yang M, Potts PR: MAGE-RING protein complexes comprise a family of E3 ubiquitin ligases. Mol Cell 2010, 39:963-974.

14. Hao YH, Doyle JM, Ramanathan S, Gomez TS, Jia D, Xu M, Chen ZJ, Billadeau DD, Rosen MK, Potts PR: Regulation of WASH-dependent actin polymerization and protein trafficking by ubiquitination. Cell 2013, 152:1051-1064.

- This report illustrates a role for MAGE proteins in regulating the subcellular localization of E3 ubiquitin ligases and shows the ability of MAGE-RING ligases to promote non-degradative K63-linked ubiquitination of substrates.

15. Pineda CT, Ramanathan S, Fon Tacer K, Weon JL, Potts MB, Ou YH, White MA, Potts PR: Degradation of AMPK by a cancer-specific ubiquitin ligase. Cell 2015, 160:715-728.

-• This study shows that MAGE-A3/6 alone is sufficient to promote anchorage-independent growth in a non-transformed, human epithelial line and that MAGE-A3/6 can recruit the alpha catalytic subunit of AMPK for ubiquitination and degradation by TRIM28, decreasing overall autophagy levels. 
16. Zhang S, Zhai X, Wang G, Feng J, Zhu H, Xu L, Mao G, Huang J: High expression of MAGE-A9 in tumor and stromal cells of non-small cell lung cancer was correlated with patient poor survival. Int J Clin Exp Pathol 2015, 8:541-550.

17. Yang F, Zhou X, Miao X, Zhang T, Hang X, Tie R, Liu N, Tian F, Wang F, Yuan J: MAGEC2, an epithelial-mesenchymal transition inducer, is associated with breast cancer metastasis. Breast Cancer Res Treat 2014, 145:23-32.

18. Daudi S, Eng KH, Mhawech-Fauceglia P, Morrison C, Miliotto A, Beck A, Matsuzaki J, Tsuji T, Groman A, Gnjatic S, et al.: Expression and immune responses to MAGE antigens predict survival in epithelial ovarian cancer. PLoS One 2014, 9:e104099.

- This work analyzed 400 epithelial ovarian cancers (EOC) for MAGE expression patterns and 285 serum samples to assess spontaneous humoral response to MAGEs and found that MAGE-A1 and -A10 were associated with poor clinical outcomes but MAGE-C1 was correlated with increased progression-free survival. In addition, the presence of MAGEspecific antibodies was found to be correlated with poor overall survival in EOC.

19. Xu Y, Wang C, Zhang Y, Jia L, Huang J: Overexpression of MAGE-A9 Is Predictive of Poor Prognosis in Epithelial Ovarian Cancer. Sci Rep 2015, 5:12104.

- This study examined the expression of MAGE-A9 in $\geq 20$ samples each for epithelial ovarian carcinomas and normal ovary/fallopian tissue by RT-PCR and >100 samples each for carcinomas and normal ovary/fallopian tissue by immunohistochemistry on tissue microarrays. MAGE-A9 was found to be significantly correlated with high grade status, CA125 levels, metastasis, and overall survival.

20. Jeon $\mathrm{CH}$, Kim IH, Chae HD: Prognostic value of genetic detection using CEA and MAGE in peritoneal washes with gastric carcinoma after curative resection: result of a 3-year follow-up. Medicine (Baltimore) 2014, 93:e83.

21. Gu X, Fu M, Ge Z, Zhan F, Ding Y, Ni H, Zhang W, Zhu Y, Tang X, Xiong L, et al.: High expression of MAGE-A9 correlates with unfavorable survival in hepatocellular carcinoma. Sci Rep 2014, 4:6625.

22. Yang B, O'Herrin S, Wu J, Reagan-Shaw S, Ma Y, Nihal M, Longley BJ: Select cancer testes antigens of the MAGE-A, -B, and -C families are expressed in mast cell lines and promote cell viability in vitro and in vivo. J Invest Dermatol 2007, 127:267-275.

23. Atanackovic D, Hildebrandt Y, Jadczak A, Cao Y, Luetkens T, Meyer S, Kobold S, Bartels $\mathrm{K}$, Pabst C, Lajmi N, et al.: Cancer-testis antigens MAGE-C1/CT7 and MAGE-A3 promote the survival of multiple myeloma cells. Haematologica 2010, 95:785-793.

24. Yang B, O'Herrin SM, Wu J, Reagan-Shaw S, Ma Y, Bhat KM, Gravekamp C, Setaluri V, Peters N, Hoffmann FM, et al.: MAGE-A, mMage-b, and MAGE-C proteins form 
complexes with KAP1 and suppress p53-dependent apoptosis in MAGE-positive cell lines. Cancer Res 2007, 67:9954-9962.

25. Liu W, Cheng S, Asa SL, Ezzat S: The melanoma-associated antigen A3 mediates fibronectin-controlled cancer progression and metastasis. Cancer Res 2008, 68:81048112.

26. Bhatia N, Xiao TZ, Rosenthal KA, Siddiqui IA, Thiyagarajan S, Smart B, Meng Q, Zuleger CL, Mukhtar H, Kenney SC, et al.: MAGE-C2 promotes growth and tumorigenicity of melanoma cells, phosphorylation of KAP1, and DNA damage repair. J Invest Dermatol 2013, 133:759-767.

- This study demonstrated that MAGE-C2 is required for melanoma viability and knockdown can reduce tumor growth in vivo. In addition, MAGE-C2 was found to induce KAP1-Ser824 phosphorylation in a ATM-dependent manner and promote DNA repair after endonuclease exposure.

27. Nardiello T, Jungbluth AA, Mei A, Diliberto M, Huang X, Dabrowski A, Andrade VC, Wasserstrum R, Ely S, Niesvizky R, et al.: MAGE-A inhibits apoptosis in proliferating myeloma cells through repression of Bax and maintenance of survivin. Clin Cancer Res 2011, 17:4309-4319.

28. Marcar L, Maclaine NJ, Hupp TR, Meek DW: Mage-A cancer/testis antigens inhibit p53 function by blocking its interaction with chromatin. Cancer Res 2010, 70:10362-10370.

29. Monte M, Simonatto M, Peche LY, Bublik DR, Gobessi S, Pierotti MA, Rodolfo M, Schneider C: MAGE-A tumor antigens target p53 transactivation function through histone deacetylase recruitment and confer resistance to chemotherapeutic agents. Proc Natl Acad Sci U S A 2006, 103:11160-11165.

30. Peche LY, Scolz M, Ladelfa MF, Monte M, Schneider C: MageA2 restrains cellular senescence by targeting the function of PMLIV/p53 axis at the PML-NBs. Cell Death Differ 2012, 19:926-936.

31. Hardie DG, Ross FA, Hawley SA: AMPK: a nutrient and energy sensor that maintains energy homeostasis. Nat Rev Mol Cell Biol 2012, 13:251-262.

32. Hardie DG: Molecular Pathways: Is AMPK a Friend or a Foe in Cancer? Clin Cancer Res 2015.

33. Choi AM, Ryter SW, Levine B: Autophagy in human health and disease. $N$ Engl J Med 2013, 368:651-662.

34. Wei Y, Zou Z, Becker N, Anderson M, Sumpter R, Xiao G, Kinch L, Koduru P, Christudass CS, Veltri RW, et al.: EGFR-mediated Beclin 1 phosphorylation in autophagy suppression, tumor progression, and tumor chemoresistance. Cell 2013, 154:1269-1284. 
35. White E: Deconvoluting the context-dependent role for autophagy in cancer. Nat Rev Cancer 2012, 12:401-410.

36. Kasznicki J, Sliwinska A, Drzewoski J: Metformin in cancer prevention and therapy. Ann Transl Med 2014, 2:57.

37. Baselga J, Campone M, Piccart M, Burris HA, 3rd, Rugo HS, Sahmoud T, Noguchi S, Gnant M, Pritchard KI, Lebrun F, et al.: Everolimus in postmenopausal hormone-receptorpositive advanced breast cancer. $N$ Engl J Med 2012, 366:520-529.

38. Bai S, He B, Wilson EM: Melanoma antigen gene protein MAGE-11 regulates androgen receptor function by modulating the interdomain interaction. Mol Cell Biol 2005, 25:1238-1257.

39. Bai S, Wilson EM: Epidermal-growth-factor-dependent phosphorylation and ubiquitinylation of MAGE-11 regulates its interaction with the androgen receptor. $\mathrm{Mol}$ Cell Biol 2008, 28:1947-1963.

40. Aprelikova O, Pandolfi S, Tackett S, Ferreira M, Salnikow K, Ward Y, Risinger JI, Barrett JC, Niederhuber J: Melanoma antigen-11 inhibits the hypoxia-inducible factor prolyl hydroxylase 2 and activates hypoxic response. Cancer Res 2009, 69:616-624.

41. Yin B, Zeng Y, Liu G, Wang X, Wang P, Song Y: MAGE-A3 is highly expressed in a cancer stem cell-like side population of bladder cancer cells. Int J Clin Exp Pathol 2014, 7:2934-2941.

42. Yamada R, Takahashi A, Torigoe T, Morita R, Tamura Y, Tsukahara T, Kanaseki T, Kubo T, Watarai K, Kondo T, et al.: Preferential expression of cancer/testis genes in cancer stemlike cells: proposal of a novel sub-category, cancer/testis/stem gene. Tissue Antigens 2013, 81:428-434.

43. Wienand K, Shires K: The use of MAGE C1 and flow cytometry to determine the malignant cell type in multiple myeloma. PLoS One 2015, 10:e0120734.

- This work examined MAGE-C1 expression in different stages of B cell development in multiple myeloma in bone marrow and peripheral blood and determined that MAGE-C1 expression is expressed most commonly in $\mathrm{CD} 34^{+}$early stem cells and pro/pre-B cells, as well as in mature proliferating plasma cells.

44. Atanackovic D, Luetkens T, Hildebrandt Y, Arfsten J, Bartels K, Horn C, Stahl T, Cao Y, Zander AR, Bokemeyer $C$, et al.: Longitudinal analysis and prognostic effect of cancertestis antigen expression in multiple myeloma. Clin Cancer Res 2009, 15:1343-1352.

45. Andrade VC, Vettore AL, Felix RS, Almeida MS, Carvalho F, Oliveira JS, Chauffaille ML, Andriolo A, Caballero OL, Zago MA, et al.: Prognostic impact of cancer/testis antigen expression in advanced stage multiple myeloma patients. Cancer Immun 2008, 8:2. 
46. Weber J, Salgaller M, Samid D, Johnson B, Herlyn M, Lassam N, Treisman J, Rosenberg SA: Expression of the MAGE-1 tumor antigen is up-regulated by the demethylating agent 5-aza-2'-deoxycytidine. Cancer Res 1994, 54:1766-1771.

47. De Smet C, Lurquin C, Lethe B, Martelange V, Boon T: DNA methylation is the primary silencing mechanism for a set of germ line- and tumor-specific genes with a CpG-rich promoter. Mol Cell Biol 1999, 19:7327-7335.

48. Schwarzenbach H, Eichelser C, Steinbach B, Tadewaldt J, Pantel K, Lobanenkov V, Loukinov D: Differential regulation of MAGE-A1 promoter activity by BORIS and Sp1, both interacting with the TATA binding protein. BMC Cancer 2014, 14:796.

49. Wischnewski F, Pantel K, Schwarzenbach H: Promoter demethylation and histone acetylation mediate gene expression of MAGE-A1, -A2, -A3, and -A12 in human cancer cells. Mol Cancer Res 2006, 4:339-349.

50. Yang B, Wu J, Maddodi N, Ma Y, Setaluri V, Longley BJ: Epigenetic control of MAGE gene expression by the KIT tyrosine kinase. J Invest Dermatol 2007, 127:2123-2128.

51. Kondo T, Zhu X, Asa SL, Ezzat S: The cancer/testis antigen melanoma-associated antigen-A3/A6 is a novel target of fibroblast growth factor receptor 2-IIIb through histone H3 modifications in thyroid cancer. Clin Cancer Res 2007, 13:4713-4720.

52. Khwaja A, Rodriguez-Viciana P, Wennstrom S, Warne PH, Downward J: Matrix adhesion and Ras transformation both activate a phosphoinositide 3-OH kinase and protein kinase B/Akt cellular survival pathway. EMBO J 1997, 16:2783-2793.

53. Hadari YR, Gotoh N, Kouhara H, Lax I, Schlessinger J: Critical role for the dockingprotein FRS2 alpha in FGF receptor-mediated signal transduction pathways. Proc Natl Acad Sci U S A 2001, 98:8578-8583.

54. Linnekin D: Early signaling pathways activated by c-Kit in hematopoietic cells. Int J Biochem Cell Biol 1999, 31:1053-1074.

55. Schlaepfer DD, Hanks SK, Hunter T, van der Geer P: Integrin-mediated signal transduction linked to Ras pathway by GRB2 binding to focal adhesion kinase. Nature 1994, 372:786-791.

56. Kouhara H, Hadari YR, Spivak-Kroizman T, Schilling J, Bar-Sagi D, Lax I, Schlessinger J: A lipid-anchored Grb2-binding protein that links FGF-receptor activation to the Ras/MAPK signaling pathway. Cell 1997, 89:693-702.

57. Vatolin S, Abdullaev Z, Pack SD, Flanagan PT, Custer M, Loukinov DI, Pugacheva E, Hong JA, Morse H, 3rd, Schrump DS, et al.: Conditional expression of the CTCF-paralogous transcriptional factor BORIS in normal cells results in demethylation and derepression of MAGE-A1 and reactivation of other cancer-testis genes. Cancer Res 2005, 65:77517762. 
58. De Smet C, Courtois SJ, Faraoni I, Lurquin C, Szikora JP, De Backer O, Boon T:

Involvement of two Ets binding sites in the transcriptional activation of the MAGE1 gene. Immunogenetics 1995, 42:282-290.

59. Wischnewski F, Friese O, Pantel K, Schwarzenbach H: Methyl-CpG binding domain proteins and their involvement in the regulation of the MAGE-A1, MAGE-A2, MAGEA3, and MAGE-A12 gene promoters. Mol Cancer Res 2007, 5:749-759.

60. Tyagi P, Mirakhur B: MAGRIT: the largest-ever phase III lung cancer trial aims to establish a novel tumor-specific approach to therapy. Clin Lung Cancer 2009, 10:371-374.

61. Ruiz R, Hunis B, Raez LE: Immunotherapeutic agents in non-small-cell lung cancer finally coming to the front lines. Curr Oncol Rep 2014, 16:400.

• Reports the findings of the large phase III MAGRIT clinical trial showing no improvement in progression-free survival in lung cancer patients treated with MAGE-A3 antigen.

62. Linette GP, Stadtmauer EA, Maus MV, Rapoport AP, Levine BL, Emery L, Litzky L, Bagg A, Carreno BM, Cimino PJ, et al.: Cardiovascular toxicity and titin cross-reactivity of affinity-enhanced $\mathbf{T}$ cells in myeloma and melanoma. Blood 2013, 122:863-871.

63. Morgan RA, Chinnasamy N, Abate-Daga D, Gros A, Robbins PF, Zheng Z, Dudley ME, Feldman SA, Yang JC, Sherry RM, et al.: Cancer regression and neurological toxicity following anti-MAGE-A3 TCR gene therapy. J Immunother 2013, 36:133-151.

- This study along with the previous report that anti-MAGE-A3 TCR therapy has cardiotoxciity due to cross-reactivity and neurological toxicity due to low level expression of MAGE-A12 in the brain.

64. Kozakova L, Vondrova L, Stejskal K, Charalabous P, Kolesar P, Lehmann AR, Uldrijan S, Sanderson CM, Zdrahal Z, Palecek JJ: The melanoma-associated antigen 1 (MAGEA1) protein stimulates the E3 ubiquitin-ligase activity of TRIM31 within a TRIM31MAGEA1-NSE4 complex. Cell Cycle 2015, 14:920-930.

65. Marcar L, Ihrig B, Hourihan J, Bray SE, Quinlan PR, Jordan LB, Thompson AM, Hupp TR, Meek DW: MAGE-A Cancer/Testis Antigens Inhibit MDM2 Ubiquitylation Function and Promote Increased Levels of MDM4. PLoS One 2015, 10:e0127713.

66. Xiao TZ, Suh Y, Longley BJ: MAGE proteins regulate KRAB zinc finger transcription factors and KAP1 E3 ligase activity. Arch Biochem Biophys 2014, 563:136-144.

67. Rual JF, Venkatesan K, Hao T, Hirozane-Kishikawa T, Dricot A, Li N, Berriz GF, Gibbons FD, Dreze M, Ayivi-Guedehoussou N, et al.: Towards a proteome-scale map of the human protein-protein interaction network. Nature 2005, 437:1173-1178.

68. Sasaki A, Masuda Y, Iwai K, Ikeda K, Watanabe K: A RING finger protein Praja1 regulates Dlx5-dependent transcription through its ubiquitin ligase activity for the 
Dlx/Msx-interacting MAGE/Necdin family protein, Dlxin-1. J Biol Chem 2002, 277:22541-22546.

69. Teuber J, Mueller B, Fukabori R, Lang D, Albrecht A, Stork O: The ubiquitin ligase Praja1 reduces NRAGE expression and inhibits neuronal differentiation of PC12 cells. PLoS One 2013, 8:e63067.

70. Kendall SE, Battelli C, Irwin S, Mitchell JG, Glackin CA, Verdi JM: NRAGE mediates p38 activation and neural progenitor apoptosis via the bone morphogenetic protein signaling cascade. Mol Cell Biol 2005, 25:7711-7724.

71. Jordan BW, Dinev D, LeMellay V, Troppmair J, Gotz R, Wixler L, Sendtner M, Ludwig S, Rapp UR: Neurotrophin receptor-interacting mage homologue is an inducible inhibitor of apoptosis protein-interacting protein that augments cell death. J Biol Chem 2001, 276:39985-39989.

72. Mouri A, Sasaki A, Watanabe K, Sogawa C, Kitayama S, Mamiya T, Miyamoto Y, Yamada K, Noda Y, Nabeshima T: MAGE-D1 regulates expression of depression-like behavior through serotonin transporter ubiquitylation. J Neurosci 2012, 32:4562-4580.

73. Taylor EM, Copsey AC, Hudson JJ, Vidot S, Lehmann AR: Identification of the proteins, including MAGEG1, that make up the human SMC5-6 protein complex. Mol Cell Biol 2008, 28:1197-1206.

74. Gur I, Fujiwara K, Hasegawa K, Yoshikawa K: Necdin promotes ubiquitin-dependent degradation of PIAS1 SUMO E3 ligase. PLoS One 2014, 9:e99503.

75. Jungbluth AA, Chen YT, Busam KJ, Coplan K, Kolb D, Iversen K, Williamson B, Van Landeghem FK, Stockert E, Old LJ: CT7 (MAGE-C1) antigen expression in normal and neoplastic tissues. Int J Cancer 2002, 99:839-845.

76. Curioni-Fontecedro A, Nuber N, Mihic-Probst D, Seifert B, Soldini D, Dummer R, Knuth A, van den Broek M, Moch H: Expression of MAGE-C1/CT7 and MAGE-C2/CT10 predicts lymph node metastasis in melanoma patients. PLoS One 2011, 6:e21418.

77. Hou SY, Sang MX, Geng CZ, Liu WH, Lu WH, Xu YY, Shan BE: Expressions of MAGEA9 and MAGE-A11 in breast cancer and their expression mechanism. Arch Med Res 2014, 45:44-51.

78. Chen YT, Ross DS, Chiu R, Zhou XK, Chen YY, Lee P, Hoda SA, Simpson AJ, Old LJ, Caballero $\mathrm{O}$, et al.: Multiple cancer/testis antigens are preferentially expressed in hormone-receptor negative and high-grade breast cancers. PLoS One 2011, 6:e17876.

79. Zhang S, Zhou X, Yu H, Yu Y: Expression of tumor-specific antigen MAGE, GAGE and BAGE in ovarian cancer tissues and cell lines. BMC Cancer 2010, 10:163. 
80. Li M, Yuan YH, Han Y, Liu YX, Yan L, Wang Y, Gu J: Expression profile of cancer-testis genes in 121 human colorectal cancer tissue and adjacent normal tissue. Clin Cancer Res 2005, 11:1809-1814.

\section{Figure Legends}

Figure 1. The MAGE protein family. Phylogenetic tree of eukaryotic MAGEs. Note, all nonmammalian MAGEs cluster together (black). Mammalian MAGEs have dramatically expanded in number and cluster into type II (pink) MAGEs that are anatomically broadly expressed and type I (MAGE-A, MAGE-B, and MAGE-C subfamilies) that are primarily restricted to expression in testis, ovary, and placenta.

Figure 2. MAGE proteins structure and function. (A) List of human MAGE proteins and their known common domain, the MAGE homology domain (MHD). Note that a few MAGEs have truncated MHDs. MAGEs that are likely pseudogenes are not listed. (B-D) Crystal structures of MAGE-A3 (B), MAGE-A4 (C), and MAGE-G1 in complex with the NSE1 E3 ubiquitin ligase (D) are shown. The two winged-helix motifs (WH-A and WH-B) that form the MHD are noted. Note the change in the relative orientation of WH-A and WH-B motifs in MAGE-A3/-A4 compared to MAGE-G1 bound to NSE1. (E) Summary of known biochemical and cellular functions of MAGEs. 


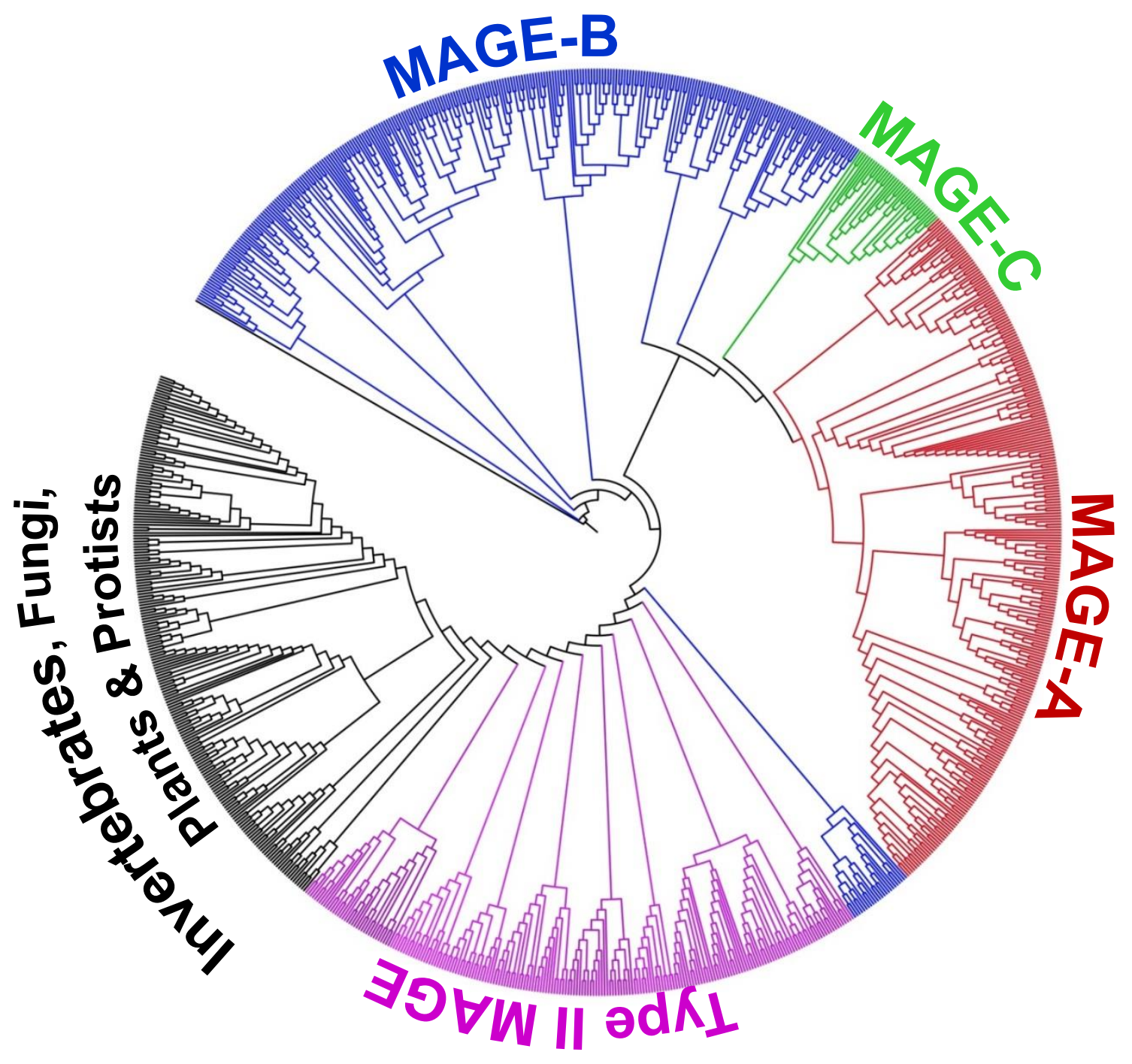

Figure 1 
A

Type I

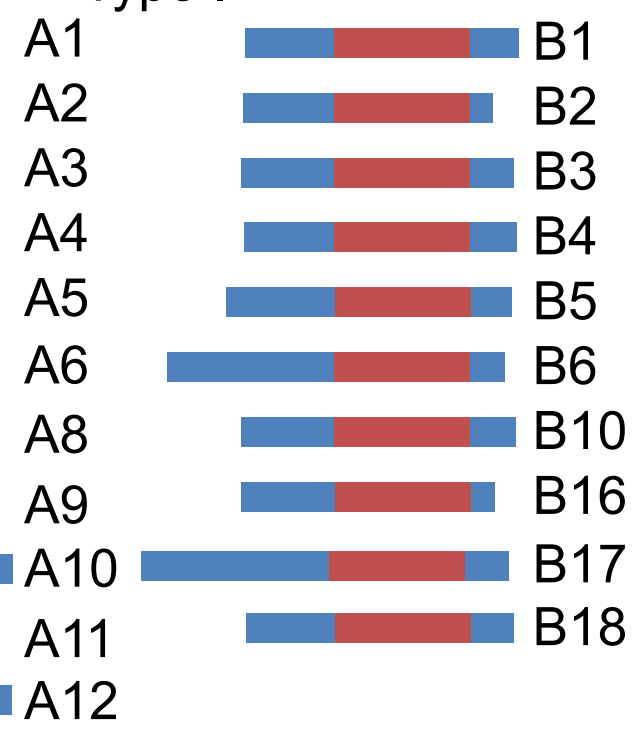

C1

C2

C3

Type II

D1

D2

D3

D4

E1

E2

F1

G1

$\mathrm{H} 1$

L2

Necdin

MHD

Truncated MHD $\quad \overline{100}$ aa

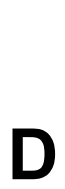

B

C

D

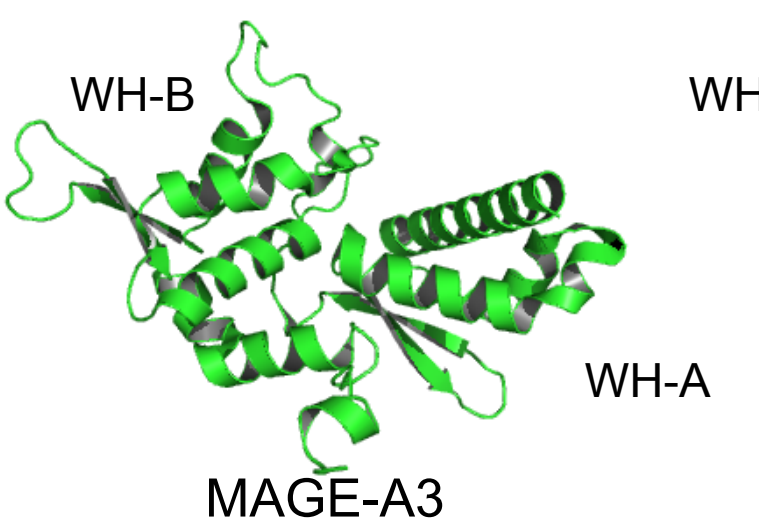

(4V0P)

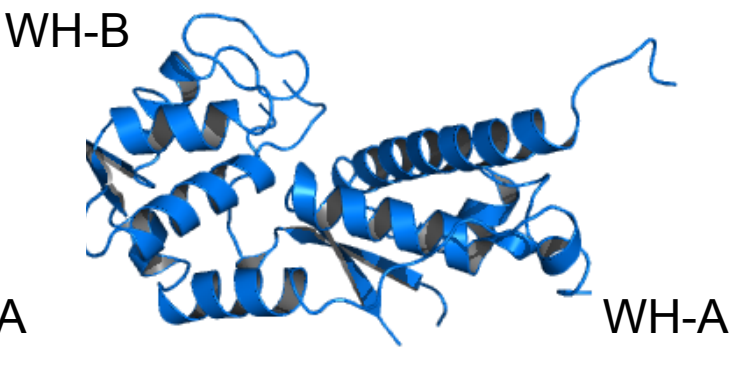

MAGE-A4

(2WA0)

E

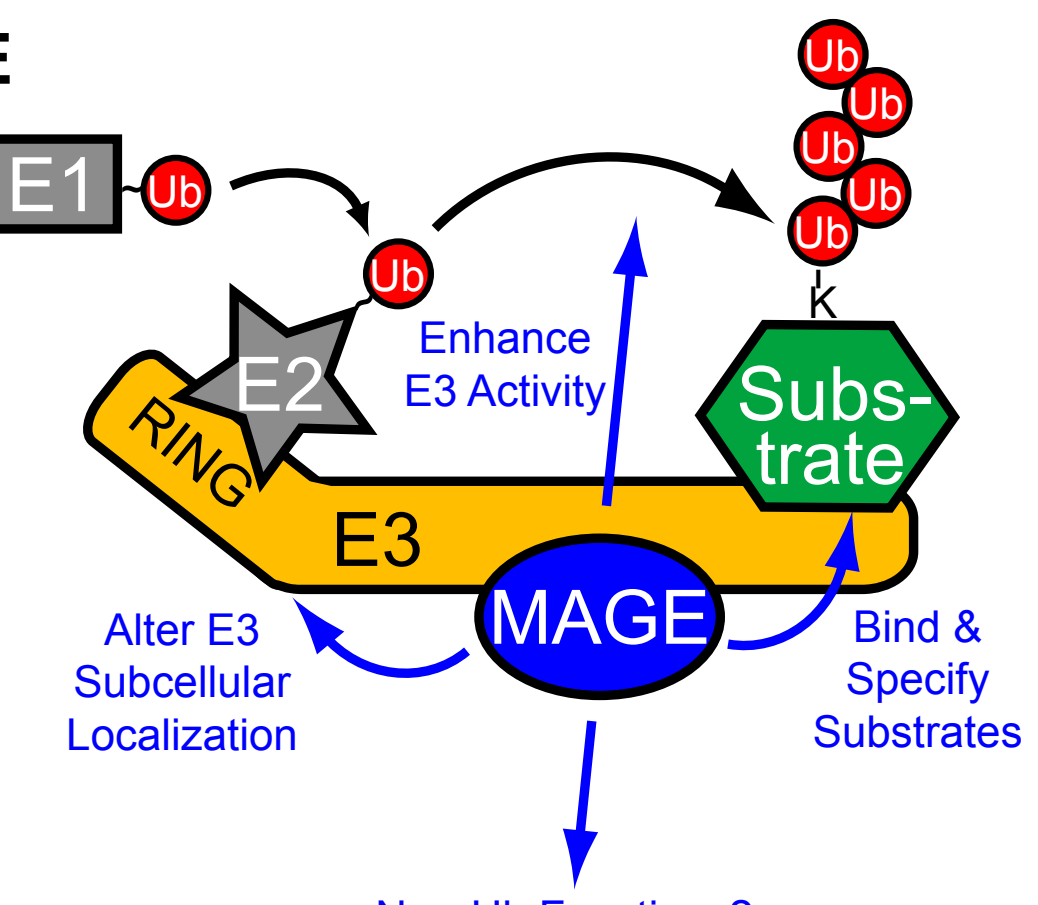

Non-Ub Functions?

Transcription, etc...

Figure 2 